\title{
Hearing in the crepuscular owl butterfly (Caligo eurilochus, Nymphalidae)
}

Kathleen M. Lucas ${ }^{1,4}$, Jennifer K. Mongrain ${ }^{1}$, James F.C. Windmill ${ }^{2}$, Daniel Robert ${ }^{3}$, and Jayne E. Yack ${ }^{1}$

${ }^{1}$ Department of Biology, Carleton University, Ottawa, Ontario, K1S 5B6, Canada

${ }^{2}$ Centre for Ultrasonic Engineering, Department of Electronic and Electrical Engineering, University of Strathclyde, Glasgow, G1 1XW, UK

${ }^{3}$ School of Biological Sciences, University of Bristol, Bristol, BS8 1UG, UK

${ }^{4}$ Present Address and Address of Correspondence: Department of Biology, University of Ottawa, Ottawa, Ontario, K1N 6N5, Canada; e-mail: kathleen.lucas@ uottawa.ca, tel: 613-5625800 ext. 6012, fax: 613-562-5486) 


\section{Summary/Abstract}

Tympanal organs are widespread in Nymphalidae butterflies, with a great deal of variability in the morphology of these ears. How this variation reflects differences in hearing physiology is not currently understood. This study provides the first examination of hearing organs in the crepuscular owl butterfly, Caligo eurilochus. We examined the tuning and sensitivity of the C. eurilochus hearing organ, called Vogel's organ, using laser Doppler vibrometry and extracellular neurophysiology. We show that the $C$. eurilochus ear responds to sound and is most sensitive to frequencies between $1-4 \mathrm{kHz}$, as confirmed by both the vibration of the tympanal membrane and the physiological response of the associated nerve branches. In comparison to the hearing of its diurnally active relative, Morpho peleides, C. eurilochus has a narrower frequency range with higher auditory thresholds. Hypotheses explaining the function of hearing in this crepuscular butterfly are discussed.

Keywords: Butterfly, Nymphalidae, tympanal hearing, scanning laser vibrometry, extracellular nerve recording 


\section{Introduction}

Butterflies are popular study organisms, in part due to their bright colours, day-flying habits, and their association with flowers and warm sunny days. In accordance with these life history traits, butterflies have well-developed visual and chemosensory systems, and there has been extensive research on these senses (Hallberg and Poppy 2003; Warrant et al. 2003). Some butterflies have well developed ears; however, surprisingly little is known about this sensory modality. This is in contrast to the related moths that make up the remainder of the order Lepidoptera, which have been the focus of research in acoustic communication for decades (Spangler 1988; Scoble 1996; Minet and Surlykke 2003; Yack 2004). Moth ears have evolved primarily as high-frequency $(>20 \mathrm{kHz})$ detectors, in response to predation pressure from insectivorous bats (Minet and Surlykke 2003). There are relatively few studies on the hearing of butterflies, providing only partial knowledge on the taxonomic distribution and function of hearing in this large and popular group of insects.

Butterflies are commonly recognized as species belonging to three superfamilies: the Papilionoidea (true butterflies), the Hesperioidea (skippers) and the Hedyloidea (mothbutterflies) (Ackery et al. 1999). Hearing organs have been described to date in the Hedyloidea and the Papilionoidea (Minet and Surlykke 2003). The Hedyloidea are nocturnally active, and their ears have been shown to function as bat-detectors, exhibiting behavioural and neurophysiological sensitivity to high frequency $(40-80 \mathrm{kHz}$ ) sound stimuli (Yack and Fullard 2000; Yack et al. 2007). In the Papilionoidea, tympanal ears have been noted to occur only within the family Nymphalidae to date. Nymphalidae is one of the largest butterfly families, containing approximately 6000 species found on every continent except Antarctica, and are predominantly active diurnally (DeVries 1987; Ackery et al. 1999). The nymphalid ear is called Vogel's Organ (VO), and is characterized as a membranous structure located at the base of the cubital vein on the ventral surface of the forewing, associated with tracheal air sacs and chordotonal organs (Vogel 1912). Descriptions of the VO in different species have indicated that it is widespread in certain nymphalid subfamilies including the Biblidinae, Apaturinae, and Satyrinae (Otero 1990; Mahony 2006; Lane et al. 2008), and the external morphology of these ears exhibits significant variation. Tympanal membranes vary not only in colour and thickness, appearing translucent to opaque, but also in structural complexity, ranging from being flat and 
apparently homogenous to exhibiting a dome-like membrane called a tholus (Otero 1990; Minet and Surlykke 2003; Mahony 2006; Lane et al. 2008; J. Yack, unpublished). The implications of this morphological variation are not known, and must be assessed by studying behavioural, mechanical, and neurophysiological responses to sound. Physiological and behavioural evidence has shown that diurnal nymphalid species respond to low frequencies $(<20 \mathrm{kHz}$ ) (Ribaric and Gogala 1996; Yack et al. 2000; Mahony 2006; Lane et al. 2008; Lucas et al. 2009), and these ears are hypothesized to function in detecting the flight sounds of insectivorous birds (Lane et al. 2008; Fournier et al. 2013). Conversely, the crepuscular nymphalid Manataria maculata responds behaviourally to high frequencies $(>20 \mathrm{kHz}$ ) (Rydell et al. 2003), which suggests it is listening to predatory bats.

The purpose of this study is to test the function hearing in the owl butterfly Caligo eurilochus, which possesses VO morphology that has not yet been reported and examined. This large nymphalid butterfly occurs from Mexico through Central and South America (DeVries 1987) and in contrast to most other nymphalid butterflies, is crepuscular, exhibiting activity in the low-light conditions of dawn and dusk (DeVries 1987). There is evidence that the visual system of Caligo species has become secondarily adapted to a crepuscular lifestyle (Frederiksen and Warrant 2008), but nothing is known about its hearing. The C. eurilochus VO appears anatomically simple, lacking the convex tholus that $M$. peleides and many nymphalid VOs possess (Lane et al. 2008; Minet and Surlykke 2003). Does the ear respond to low frequencies like its diurnal relative the Morpho, or does it respond to higher frequencies like other nocturnal insects? We test the sensitivity of hearing in $C$. eurilochus by conducting extracellular physiology of the auditory nerves, and measuring the vibrational response of the tympanal membrane.

\section{Materials and Methods}

\section{Animals}

Caligo eurilochus (Cramer, 1775) specimens were obtained as pupae from London Pupae Supplies (Horspath, Oxfordshire, UK; Canadian import permit P-2007-01460). At Carleton University the pupae were maintained in mesh enclosures inside a greenhouse where they were exposed to natural light levels, $70-80 \%$ humidity, and daily temperature fluctuations between 24- 
$30^{\circ} \mathrm{C}$. At the University of Bristol, pupae were maintained in mesh enclosures inside an incubator set at $28{ }^{\circ} \mathrm{C}$ and $80 \%$ humidity on a $12: 12 \mathrm{~h}$ light cycle. Upon eclosion, butterflies were transferred to a larger flight cage and provided with fermented fruit until they were used for experiments (within 1-5 days).

\section{Morphology of VO}

The external morphology of the VO tympanal membrane was examined using light and scanning electron microscopy. Its length, width, and surface area were measured in males and females using an Olympus SZX12 light microscope (Olympus, Tokyo, Japan) equipped with a Zeiss (Oberkochen Germany) AxioCamMRc5 camera (1.4 megapixels, 1388 x 1040) and AxioVision AC (version 4.6) software. Auditory nerve branches were dissected using previous methods (see Lane et al. 2008). For scanning electron microscopy, the VO was dissected from fresh specimens, dried and mounted on aluminum stubs, sputter-coated with gold-palladium, and examined with a JEOL (Tokyo, Japan) JSM-6400 scanning electron microscope.

\section{Neurophysiology}

Butterflies were tethered ventral side down on a block of modelling clay, ensuring the VO was unobstructed by placing the forewing on top of the hind wing and trimming the wings to $\sim 2 \mathrm{~cm}$ in length. A groove of approximately $1.5 \mathrm{~cm}$ depth and width was made in the clay to allow passage of the sounds to the ear. The animals were oriented as such since the wing nerve IIN1c had to be accessed dorsally by removing the tegula and associated membrane. The nerve IIN1c branches into N.I, N.II, and N.III, each of which were tested both individually and together using a stainless steel hook electrode referenced to a second stainless steel electrode

placed in the thorax. Once a neural signal was detected, unused nerve branches were cut and the preparation was covered in silicon grease (Dow Corning, Midland, Mich., USA) to prevent desiccation. Neural signals were amplified with a Grass P15 AC preamplifier (West Warwick, RI, USA) and displayed on a Tektronix (Beaverton, ON, Canada) THS720A oscilloscope. Neural activity and sound stimuli (see below) were recorded simultaneously as .wav files on a Fostex 
FR-2 field memory recorder at a sampling rate of $48 \mathrm{kHz}$ (Gardena, CA, USA). All recordings were performed in a Faraday cage lined with acoustic foam $(1.22 \times 0.89 \times 0.84 \mathrm{~m})$.

Acoustic stimuli were presented as pure tone trapezoidal sound pulses (30 ms duration, 5ms rise/fall, linear ramp) shaped using PC Tucker Davis Technologies (TDT) software (RpvdsEx, v. 5.4, Alachua, FL, USA) and synthesized by a TDT RX6 multifunction processor. Responses were obtained for frequencies $<30 \mathrm{kHz}$ to construct audiograms (see below). Low frequency sounds $(0.1$ to $3 \mathrm{kHz})$ were amplified by a TDT SA1 stereo power amp and broadcast from a CWR 200B50 woofer (Q components, Waterloo, ON) positioned on a stand outside of the recording chamber (at $80 \mathrm{~cm}$ ). The sound pressure level of the stimuli between 3 and $30 \mathrm{kHz}$ were controlled with a TDE PA5 programmable attenuator and broadcast from a two-inch cone tweeter (GT-1016, Q components). Sound levels were calibrated to dB SPL (reference pressure $20 \mu \mathrm{Pa}$ ) by broadcasting a 1-second sine wave to a Brüel \& Kjær (B\&K) Type 2239 sound level meter (Brüel \& Kjær, Nærum, Denmark) or a B\&K Type $41356.35 \mathrm{~mm}$ microphone and type 2610 B\&K measuring amplifier.

To assess the intensity response of the VO nerves, sound stimuli at one frequency were presented at $5 \mathrm{~dB}$ below threshold, and increased by $5 \mathrm{~dB}$ steps to the maximum output of the speaker. Neural waveforms in response to ten stimuli at each intensity level were recorded as stated above. Analyses, including averaging over the ten replicates and determination of neural latencies were accomplished using Matlab (v. R2010a; Mathworks, Natick, Mass., USA).

Audiograms were constructed from N.II and N.III both individually and together. Frequencies between 0.5 and $30 \mathrm{kHz}$ were tested in random order at $0.5-1 \mathrm{kHz}$ intervals. To determine the auditory thresholds of the $C$. eurilochus ear, the sound stimulus intensity was progressively increased until a compound action potential waveform could be confirmed in two ways: (1) observed on a Tektronix (Beaverton, ON, Canada) THS720A oscilloscope at twice the background noise with a short latency following the stimulus pulse, and (2) detected by a audiomonitor in synchrony with the loudspeaker by two independent observers. This online method as been previously used to assess auditory thresholds in butterfly ears (Lane et al. 2008; Lucas et al., 2009; Fournier et al., 2013). Frequencies were tested in random order, with initial frequencies re-tested to ensure the preparation and recording had remained stable throughout the procedure. Auditory thresholds from 12 individuals (nine males and three females) were tested, 
providing a total of 15 audiograms (including both left and right VOs from one male and two females).

\section{Laser Vibrometry}

The mechanical response of the VO tympanal membrane was investigated using a microscanning laser Doppler vibrometer. Animals were positioned upright, attached ventral side down to a brass bar $(5 \times 1 \times 60 \mathrm{~mm})$ on an adjustable holder for easy alignment using Blu-tack® (Bostik-Findley, Stafford, UK), with wings clasped above using a paper clip to expose the VO. The tympanal membrane vibrations (one VO per animal) were examined in response to broadband periodic chirp signals between $0.1-1 \mathrm{kHz}$ and $1-30 \mathrm{kHz}$, produced by the Polytec Scanning Vibrometer software (version 7.4, Polytec Gmbh, Waldbronn, Germany). This frequency range was chosen to encompass the hearing range of $C$. eurilochus as determined from neurophysiological recordings. Sounds were generated using a PCI data acquisition board (PCI4451; National Instruments, Austin, TX, USA), amplified (Model TAFE570; Sony, Tokyo, Japan), and projected from one of two loudspeakers (1-30kHz: ESS AMT-1, ESS Laboratory inc., Sacramento, CA, USA; 0.1-1 kHz: AP100MO, diameter: $117 \mathrm{~mm}$, AUDAX, Chateau du Loir, France). The sound pressure level of the acoustic stimulus, projected from the loudspeaker positioned approximately $20 \mathrm{~cm}$ from the specimen, was recorded simultaneously next to the VO using a calibrated B\&K Type 4138 condenser pressure microphone and a B\&K 2633 preamplifier. Recordings were made when the sound was at approximately 18-20 mPa (where 20 $\mathrm{mPa}$ corresponds to $60 \mathrm{~dB}$ SPL), with constant amplitude across the range of frequencies (computer corrected, as described in (Windmill et al. 2005)). Signals were sampled at $102.4 \mathrm{kHz}$, and a frequency spectrum was produced for each signal with a resolution of $12.5 \mathrm{~Hz}$ using a fast Fourier transform with a rectangular window using the Polytec Scanning Vibrometer software.

At the beginning of each experiment, the scan area was set to encompass the entire tympanal membrane. A single scan consisted of >200 measurement points equally spaced within the defined area, and each point was sampled 16 times throughout the scan, resulting in scan durations of approximately 7-10 minutes. Vibration velocities were measured using a microscanning laser Doppler vibrometer (PSV-300-F; Polytec, Waldbronn, Germany) with an OFV-056 scanning head fitted with a close-up video attachment, allowing for the laser spot ( 4 
$\mu \mathrm{m}$ diameter) to be positioned with an accuracy of $\sim 2 \mu \mathrm{m}$ and be constantly monitored. All experiments were carried out on a vibration isolation table (TMC 784-443-12R; Technical Manufacturing Corp., Peabody, MA, USA) at room temperature $\left(24-26{ }^{\circ} \mathrm{C}\right)$ in an acoustic isolation booth (IAC series 1204A; Industrial Acoustics, Bronx, NY, USA).

The laser and microphone signals were used to calculate the mechanical sensitivity, phase, and coherence of the tympanal responses at each scan point. Specifically, the mechanical sensitivity (nm.Pa ${ }^{-1}$ ) was calculated as the transfer function of the membrane displacement (nm) with respect to the acoustic stimulus as recorded by the reference microphone (Pa). The amount of unrelated noise in the vibrational response was estimated by calculating the magnitudesquared coherence between the vibrometer and the microphone signal (see Windmill et al., 2005). Data were considered reliable when the coherence exceeded $80 \%$.

\section{Results}

\section{External morphology and innervation of VO}

The VO in C. eurilochus is located ventrally on the forewing at the base of the cubital vein, between the subcostal and anal veins (Fig. 1a). The organ comprises a thinned region of cuticle (the tympanal membrane) that is supported by a rigid cuticular border formed by the cubital vein. The tympanal membrane is backed by tracheal air sacs. Elongated setae extend from the posterior edge of the tympanal border to provide a protective hood over the tympanal membrane (Fig. 1b). The membrane itself is oval, with an average length of $1823.3 \pm 377.7 \mu \mathrm{m}$, a width of $1074.8 \pm 87.6 \mu \mathrm{m}$, and area of $1.66 \pm 0.33 \mathrm{~mm}^{2}$ (mean \pm s.d.; $\mathrm{n}=9$ ). When observed with a light microscope, the tympanal membrane appears to be almost flat with small ridges that run along the anterior-posterior axis. The semi-transparent membrane exhibits a distinctive pigmented spot located distally on the anterior side of the membrane (Fig. 1c-d). Attachment points of three chordotonal organs are observed through the semi-transparent membrane (Fig. 1d), consistent with what is found in other nymphalid species (Yack et al. 2000; Lane et al. 2008). Nerve IIN1c splits into three main branches, N.I, N.II, and N.III, two of which (N.II and N.III) innervate the VO. These nerves are homologous to those observed in other eared Nymphalidae (Yack et al. 2000; Mahony 2006; Lane et al. 2008; Lucas et al. 2009). 
Scanning electron microscopy (SEM) reveals that the external surface of the tympanum is covered by non-socketed microtrichia (Fig. 2). These microtrichia are approximately $10-15 \mu \mathrm{m}$ in length across most of the membrane, though shorter and more sparsely distributed at the distal pigmented spot (Fig. 2b-c). The ridges in the membrane are also apparent in the SEM images. No differences were observed in external morphology between sexes.

\section{Neurophysiology}

Extracellular recordings were initially performed on all three nerve branches (N.I, N.II, and N.III) of the wing nerve IIN1c. No auditory responses were recorded from the non-auditory branch N.I (in agreement with previous recordings on M. peleides (Lane et al. 2008)). Both N.II and N.III responded to acoustic stimuli between 0.4 and $27 \mathrm{kHz}$ with best frequencies between 1$4 \mathrm{kHz}$. Neural responses in both branches consisted of compound action potentials that increased in amplitude, as well as in duration (33.3 to $36.4 \mathrm{~ms}$ ) and decreased in latency (10.0 to $8.0 \mathrm{~ms}$ ) with increasing sound levels (Fig. 3a). The neural response was confirmed to be sensory as it remained when the nerve branch was severed proximal to the location of the recording electrode, and was abolished when it was severed distally.

Fifteen audiograms were constructed for 12 C. eurilochus specimens. Audiograms were conducted on individual branches N.II or N.III, or on both branches together (N.II + N.III). Since our goal was to assess the general hearing sensitivity of the ear, and not to compare responses of individual branches, these data are pooled in our sensitivity curve (Fig. 3b). Overall, our results show that the $C$. eurilochus $\mathrm{VO}$ is most sensitive to frequencies between $1-4 \mathrm{kHz}$, with a best median threshold of $72 \mathrm{~dB}$ SPL at $4 \mathrm{kHz}$, and a best individual threshold of $61 \mathrm{~dB}$ SPL at $3 \mathrm{kHz}$. While thresholds were obtained for frequencies above $5 \mathrm{kHz}$, the sensitivity to these frequencies dropped off with thresholds above $80 \mathrm{~dB}$ SPL. Further increases in stimulus frequencies (>7.5 $\mathrm{kHz}$ ) resulted in thresholds above $90 \mathrm{~dB}$.

\section{Mechanical response of VO}

The tympanal membranes of 10 individual C. eurilochus VOs were scanned with a laser Doppler vibrometer to assess the mechanical properties in response to different sound frequencies. For all frequencies tested $(0.1-30 \mathrm{kHz})$, the membrane exhibited a single mode of vibration, with a mechanical response similar to a standing wave (as shown in Online Resource 
1, Fig. 4a). The point of maximal deflection in the vibration cycle occurred just proximal of the membrane center (Fig. 4a), at the attachment points of the more proximal chordotonal organs (Fig. 1d). The membrane vibration was most coherent and exhibited the largest displacement in response to $1-6 \mathrm{kHz}$ (Fig. 4b-c). At the position of maximal deflection (Fig. 4a) in response to a periodic chirp, the mean peak in mechanical sensitivity (membrane displacement/sound pressure) was $406 \pm 176 \mathrm{~nm} \cdot \mathrm{Pa}^{-1}$ at $2.3 \mathrm{kHz}$ (Fig. 4b). This corresponds to a mean absolute displacement of $7.4 \pm 3.2 \mathrm{~nm}$. The phase of the transfer function between the sound stimulus input and the membrane vibration output began at $60^{\circ}$ in response to $1 \mathrm{kHz}$, then fell to zero at $2.3 \mathrm{kHz}$, corresponding to the mean peak of the displacement gain (Fig. 4c). The phase continued to drop in response to higher frequencies, leveling out at approximately $100^{\circ}$ in response to frequencies above $5 \mathrm{kHz}$. This phase response is an indication of the membrane's resonant behavior. The coherence of the transfer function was well above 0.8 for frequencies below $5 \mathrm{kHz}$, while in response to frequencies above $5 \mathrm{kHz}$, it decreased though remained higher than 0.85 (Fig. 4d).

\section{Discussion}

While the VO is widespread throughout the Nymphalidae, it shows remarkable diversity in its external morphology, ranging from being absent in species such as the Monarch butterfly (Danaus plexippus), to being highly structured in others, such as the Blue Morpho (Morpho peleides) (Otero 1990; Minet and Surlykke 2003). Comparative studies of the VO allow us to examine how variation in structure reflects the sensory physiology, and can ultimately provide insights into the function and evolution of hearing in butterflies. The owl butterfly C. eurilochus studied here provides an excellent opportunity for such a comparative analysis. It possesses a VO that is less complex than other nymphalid species studied to date (Ribaric and Gogala 1996; Yack et al. 2000; Mahony 2006; Lane et al. 2008). Unlike its close relative M. peleides, which is a day flyer, C. eurilochus and other Caligo spp. are active at dawn and dusk (Srygley 1994; Penz and DeVries 2002). This shift to a crepuscular lifestyle has impacted the visual system; in $C$. memnon the visual system has a greater sensitivity to low-light conditions (Frederiksen and Warrant 2008). Despite possessing apposition eyes that are usually optimized for vision in bright light, the eyes of $C$. memnon have up to four-times greater light sensitivity due to larger eye facets when compared to M. peleides. If the adoption of a crepuscular lifestyle has led to changes in the Caligo visual system, has it also affected its auditory system? 
When compared to $M$. peleides, $C$. eurilochus exhibits high thresholds in response to sounds between $0.4-27 \mathrm{kHz}$. This poor sensitivity is most significant to frequencies greater than $10 \mathrm{kHz}$, shown both in the neural thresholds and the vibration spectrum of the tympanal membrane. While $M$. peleides exhibits auditory thresholds at a median threshold of $54 \mathrm{~dB}$ SPL (N.II branch, $\mathrm{n}=6$ ) at $4 \mathrm{kHz}$ (Lucas et al. 2009), C. eurilochus has a median threshold of $72 \mathrm{~dB}$ SPL $(n=12)$ at $3 \mathrm{kHz}$. The mechanical sensitivity of the VO tympanal membranes differs as well; while they share a similar peak in the membrane displacement spectrum between 1-5 kHz, the $M$. peleides average gain exhibits a more gradual drop-off as the frequency increases, particularly in the outer membrane. This suggests that, despite high thresholds, C. eurilochus ear is more narrowly tuned between $1-4 \mathrm{kHz}$.

At present, the function of hearing in Nymphalidae butterflies, most of which are diurnally active, remains unknown, although there is evidence that hearing functions to detect the avian predators (Fournier et al. 2013). We can speculate on the functional significance of the morphologically simpler, low frequency ear of Caligo. Our results do not support a bat-detecting role, due to the lack of sensitivity to frequencies greater than $10 \mathrm{kHz}$. Instead, Caligo spp. may avoid bats due to non-overlapping times of activity through temporal niche partitioning. Temporal niche partitioning could account for the poor auditory sensitivity observed in $C$. eurilochus; a loss of sensitivity due to release from selective pressure has been noted in other insects including flightless female mantids (Yager 1999), non-calling flightless grasshoppers (Lehmann et al. 2010), and flight-incapable crickets (Pollack and Martins 2007). Auditory regression has also been observed in moths and crickets in bat-free habitats (Fullard 1994; Fullard et al. 2007; Fullard et al. 2010), and in moths that avoid bats by changing their times of activity from night to day (Fullard et al. 1997; Surlykke et al. 1998; ter Hofstede et al. 2008). Having adopted a crepuscular lifestyle, the selective pressures acting on C. eurilochus could too have changed, leading to auditory regression. However the function of the ear has not been explicitly tested here, and as such we cannot conclude that this is indeed the case. What $C$. eurilochus might be listening to - indeed, whether it is listening to anything - remains unknown, and will be the focus of future research.

\section{Acknowledgements}


We thank Ed Bruggink (Carleton University) and Vicky Pook (University of Bristol) for help rearing the butterflies. This work was funded by a Journal of Experimental Biology Travelling Fellowship to K.M.L., the Canadian Foundation for Innovation, Ontario Innovation trust, and NSERC to J.E.Y., the BBSRC to J.F.C.W. and D.R., and the Royal Society (D.R.). 


\section{Figures}
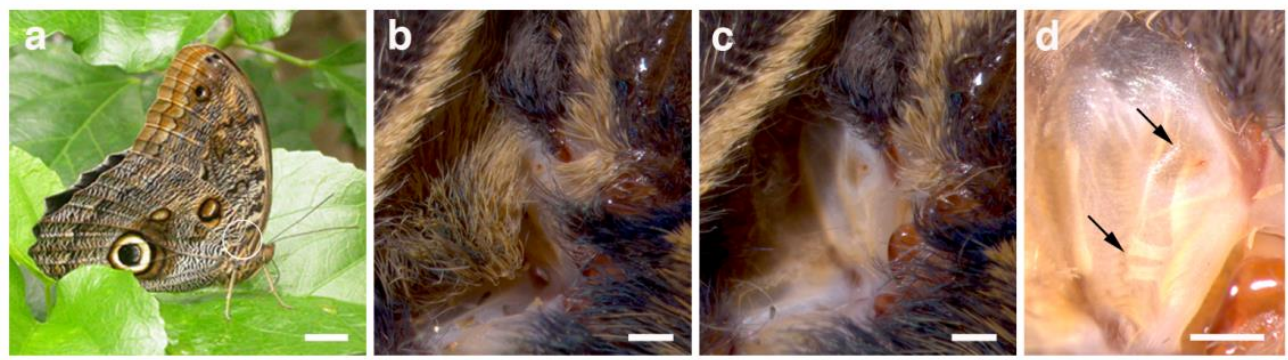

Fig 1. (a) The natural resting position of Caligo eurilochus, with the Vogel's Organ (VO) exposed on the forewing. Scale bar $=1 \mathrm{~cm}$. (b-d) Close-up of VO, where (b) shows VO in its natural state, while (c) and (d) show VO with its surrounding scales removed. The arrows in (d) indicate the attachment points of the chordotonal organs, with the top attachment point coinciding with the consistently-observed dark spot on the tympanal membrane. The orientation is the same in each image, with posterior to the left. Scale bars $=500 \mu \mathrm{m}$.

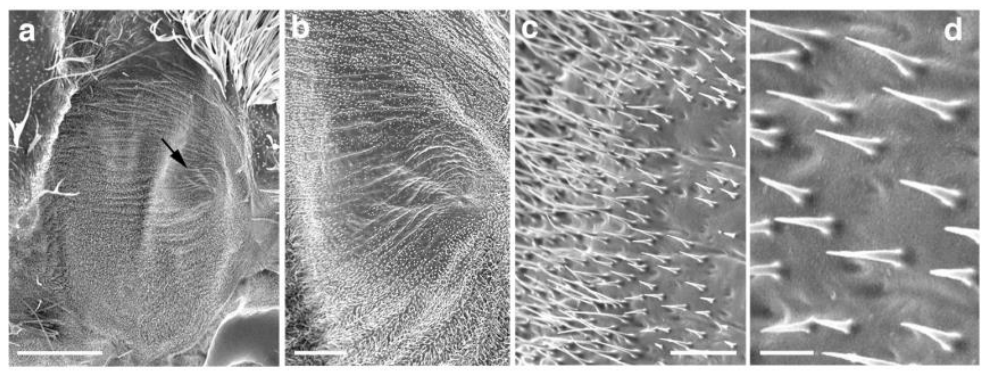

Fig 2. Scanning electron micrograph of the Caligo eurilochus Vogel's organ. (a) Whole view of the left tympanal membrane (anterior on right, distal on top). The arrow indicates the location of the dark-spot, as shown in Fig. 1d (top arrow). Scale bar $=500 \mu \mathrm{m}$. (b) Close-up of the dark spot near the distal end of the anterior side of the membrane. Scale bar $=100 \mu \mathrm{m}$. (c) Close-up of the microtrichia at the distal end of the dark-spot, showing how they diminish towards the center of the spot. Scale bar $=10 \mu \mathrm{m}$. (d) Further close-up of individual microtrichia. Scale bar $=5 \mu \mathrm{m}$. 

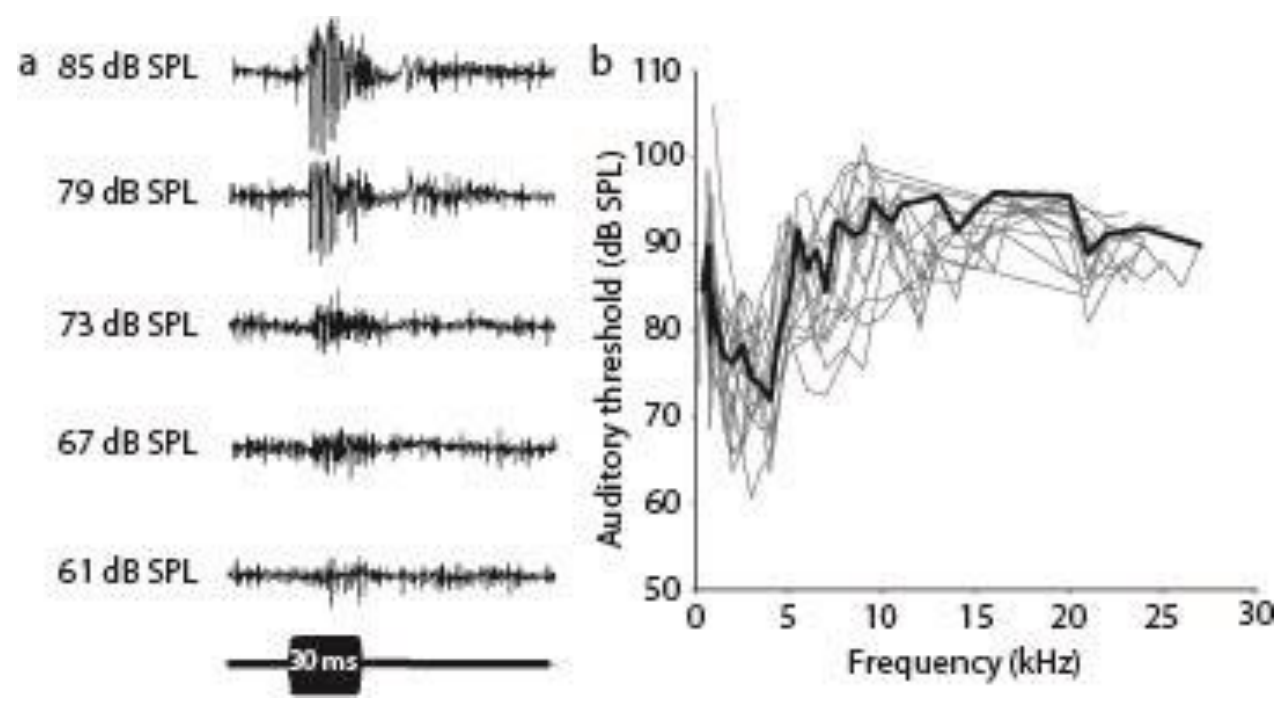

Fig 3. Neurophysiological responses. (a) Representative neural traces in a male Caligo eurilochus in response to a $2 \mathrm{kHz}$ tone, recorded from the N.III branch. Neural traces are averaged over 10 replicates. The amplitude of the response increases with the stimulus intensity, while the latency decreases. (b) Auditory thresholds recorded from nerve branches of the main auditory nerve IINc1 (N.II + N.III) in male and female C. eurilochus. Individual thresholds (grey lines) and the median threshold (black line) exhibiting responses to frequencies from $400 \mathrm{~Hz}$ to $27 \mathrm{kHz}(\mathrm{n}=15)$. The best frequency overall was $4 \mathrm{kHz}$, with a median threshold of $72 \mathrm{~dB}$ SPL, while the best individual threshold was $60 \mathrm{~dB}$ SPL at $3 \mathrm{kHz}$. 

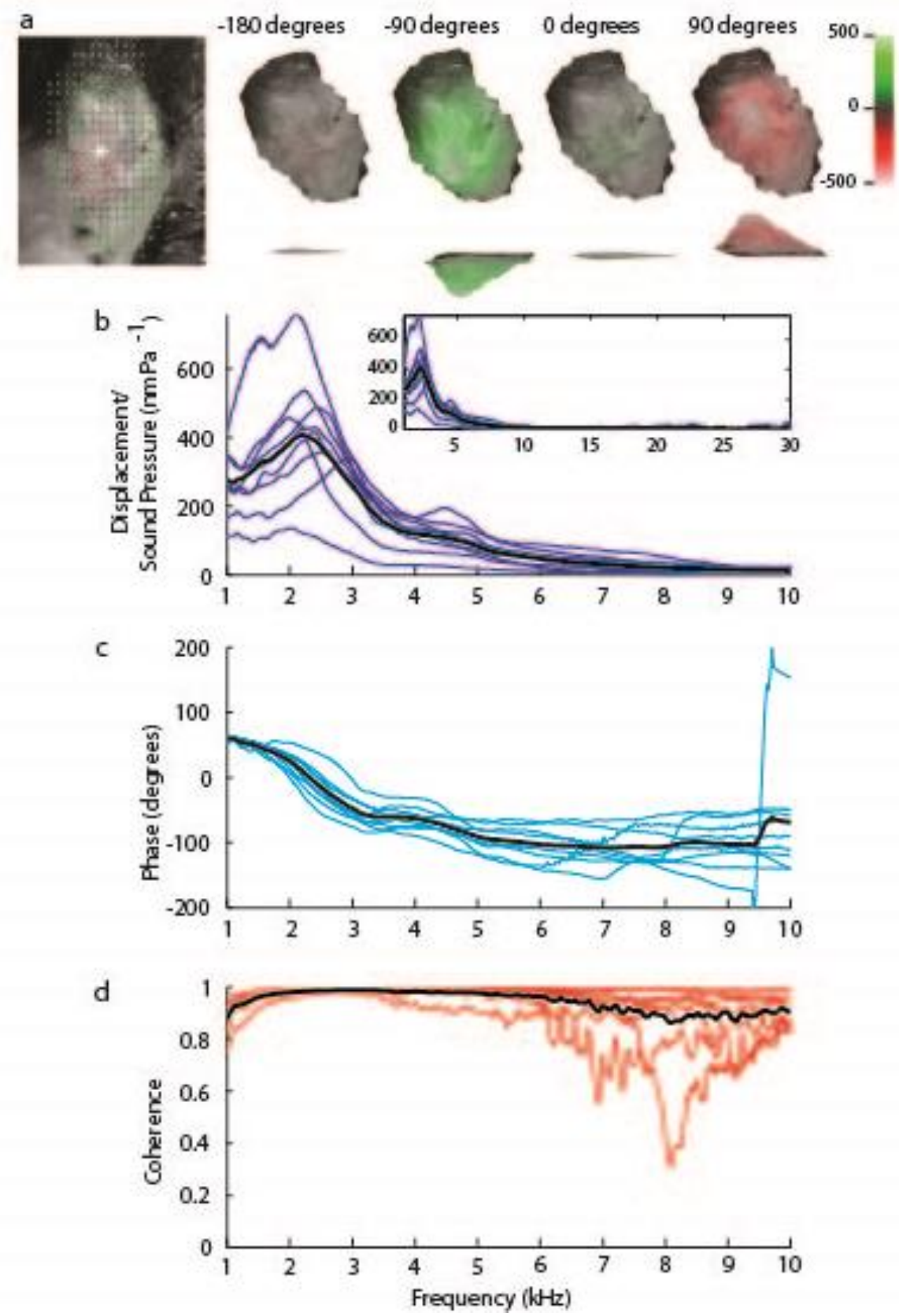

Fig 4. The vibrational response of the Caligo eurilochus tympanal membrane. (a) Area scans of the tympanal deflections in response to a $60 \mathrm{~dB}$ SPL $2.4 \mathrm{kHz}$ tone, shown for four different phases within a single oscillation period. The scanning region and test points are shown on the orientation image of the tympanal membrane (left image), with the point of maximal deflection denoted by the asterisk. The profile of the area scan is shown from both a top view and a side view. The vibration profile and point of maximal deflection as shown remained constant for all frequencies tested. (b-d) Mechanical responses of the tympanal membrane in C. eurilochus at the point of maximal deflection in response to a $1-30 \mathrm{kHz}$ periodic chirp presented at $60 \mathrm{~dB}$ SPL. 
The data for ten individuals are shown as coloured lines, and the corresponding mean is shown as a black line. Shown are the displacement gain (b), the phase (c), and the coherence (d) of the transfer function of the measured mechanical displacement and the measured sound pressure of the acoustic stimulus, indicating the membrane is most responsive to frequencies between 1-4 $\mathrm{kHz}$, with a mean peak frequency at $2.3 \mathrm{kHz}$. Inset in (b) shows the response gain to the full frequency bandwidth tested, displaying very little activity above $10 \mathrm{kHz}$.

Online Resource 1. Animation of tympanal deflections in Caligo eurilochus at $2.5 \mathrm{kHz}$. 


\section{References}

Ackery PR, de Jong R, Vane-Wright RI (1999) The Butterflies: Hedyloidea, Hesperoidea and Papilionoidea. In: Kristensen N (ed) Handbook of Zoology. Arthropoda: Insecta. Lepidoptera, Moths and Butterflies, Vol. 1. Evolution, Systematics, and Biogeography. Walter de Gruyter, Berlin, pp 263-300

DeVries PJ (1987) The Butterflies of Costa Rica and their Natural History. Vol I: Papilionoidea, Pieridae, Nymphalidae. University of Chicago Press, Chicago

Fournier JP, Dawson JW, Mikhail A, Yack JE (2013) If a bird flies in the forest, does an insect hear it? Biol Lett 9:20130319. doi: 10.1098/rsbl.2013.0319

Frederiksen R, Warrant EJ (2008) Visual sensitivity in the crepuscular owl butterfly Caligo memnon and the diurnal blue morpho Morpho peleides: a clue to explain the evolution of nocturnal apposition eyes? J Exp Biol 211:844-851. doi: 10.1242/jeb.012179

Fullard JH (1994) Auditory changes in noctuid moths endemic to a bat-free habitat. J Evol Biol 445:435-445

Fullard JH, Dawson JW, Otero LD, Surlykke A (1997) Bat-deafness in day-flying moths (Lepidoptera, Notodontidae, Dioptinae). J Comp Physiol A 181:477-483

Fullard JH, ter Hofstede HM, Ratcliffe JM, et al. (2010) Release from bats: genetic distance and sensoribehavioural regression in the Pacific field cricket, Teleogryllus oceanicus. Naturwissenschaften 97:53-61. doi: 10.1007/s00114-009-0610-1

Fullard JH, Ratcliffe JM, ter Hofstede HM (2007) Neural evolution in the bat-free habitat of Tahiti: partial regression in an anti-predator auditory system. Biol Lett 3:26-28. doi: 10.1098/rsbl.2006.0550

Hallberg E, Poppy G (2003) Exocrine glands: Chemical communication and chemical defense. In: Kristensen N (ed) Handbook of Zoology, Arthropoda, Insecta, Lepidoptera, Moths and Butterflies Vol. 2. Morphology, Physiology, and Development. Walter de Gruyter, Berlin, pp 361-375

ter Hofstede HM, Ratcliffe JM, Fullard JH (2008) Nocturnal activity positively correlated with auditory sensitivity in noctuoid moths. Biol Lett 4:262-265. doi: 10.1098/rsbl.2007.0617

Lane KA, Lucas KM, Yack JE (2008) Hearing in a diurnal, mute butterfly, Morpho peleides (Papilionoidea, Nymphalidae). J Comp Neurol 508:677-686. doi: 10.1002/cne.21675

Lehmann GUC, Berger S, Strauss J, et al. (2010) The auditory system of non-calling grasshoppers (Melanoplinae: Podismini) and the evolutionary regression of their tympanal ears. J Comp Physiol A 196:807-816. doi: 10.1007/s00359-010-0560-2

Lucas KM, Windmill JFC, Robert D, Yack JE (2009) Auditory mechanics and sensitivity in the tropical butterfly Morpho peleides (Papilionoidea, Nymphalidae). J Exp Biol 212:3533-41. doi: 10.1242/jeb.032425

Mahony S (2006) Hearing in the speckled wood butterfly, Parage aegeria (Nymphalidae: Satyrinae). M. Sc. Dissertation, Carleton University

Minet J, Surlykke A (2003) Sound producing and auditory organs. In: Kristensen NP (ed) Handbook of Zoology, Arthropoda, Insecta, Lepidoptera, Moths and Butterflies Vol. 2. Morphology, Physiology, and Development. Walter de Gruyter, Berlin, pp 289-323

Otero LD (1990) Estudio de algunos caracteres para su uso en la classificacion de Eurytelinae (Lepidoptera). Bol Entomol Venez 5:123-128 
Penz CM, DeVries PJ (2002) Phylogenetic Analysis of Morpho Butterflies (Nymphalidae, Morphinae): Implications for Classification and Natural History. Am Museum Novit No. 3374

Pollack GS, Martins R (2007) Flight and hearing: ultrasound sensitivity differs between flightcapable and flight-incapable morphs of a wing-dimorphic cricket species. J Exp Biol 210:3160-3164. doi: 10.1242/jeb.008136

Ribaric D, Gogala M (1996) Acoustic behaviour of some butterfly species of the genus Erebia (Lepidoptera: Satyridae). Acta Entomol Slov 4:5-12

Rydell J, Kaerma S, Hedelin H, Skals N (2003) Evasive response to ultrasound by the crepuscular butterfly Manataria maculata. Naturwissenschaften 90:80-83. doi: $10.1007 / \mathrm{s} 00114-002-0391-2$

Scoble MJ (1996) In search of butterfly origins: morphology and molecules. Trends Ecol Evol 11:274-275

Spangler HG (1988) Moth hearing, defense, and communication. Annu Rev Entomol 33:59-81

Srygley RB (1994) Shivering and its cost during reproductive behaviour in Neotropical owl butterflies, Caligo and Opsiphanes (Nymphalidae: Brassolinae). Anim Behav 47:23-32

Surlykke A, Skals N, Rydell J, Svensson M (1998) Sonic hearing in a diurnal geometrid moth, Archiearis parthenias, temporally isolated from bats. Naturwissenschaften 85:36-37. doi: $10.1007 / \mathrm{s} 001140050449$

Vogel R (1912) Über die Chordotonalorgane in der Wurzel der Schmetterlingsflügel. Zeitschrift fur Wissenschaftliche Zool 100:210-244

Warrant E, Kelber A, Kristensen NP (2003) Visual organs. In: Kristensen N (ed) Handbook of Zoology, Arthropoda, Insecta, Lepidoptera, Moths and Butterflies Vol. 2. Morphology, Physiology, and Development. Walter de Gruyter, Berlin, pp 325-359

Windmill JFC, Göpfert MC, Robert D (2005) Tympanal travelling waves in migratory locusts. J Exp Biol 208:157-68. doi: 10.1242/jeb.01332

Yack JE (2004) The structure and function of auditory chordotonal organs in insects. Microsc Res Tech 63:315-37. doi: 10.1002/jemt.20051

Yack JE, Fullard JH (2000) Ultrasonic hearing in nocturnal butterflies. Nature 403:265-266. doi: $10.1038 / 35002247$

Yack JE, Kalko EK V, Surlykke A (2007) Neuroethology of ultrasonic hearing in nocturnal butterflies (Hedyloidea). J Comp Physiol A 193:577-590. doi: 10.1007/s00359-007-0213-2

Yack JE, Otero LD, Dawson JW, et al. (2000) Sound production and hearing in the blue cracker butterfly Hamadryas feronia (Lepidoptera, Nymphalidae) from Venezuela. J Exp Biol 203:3689-3702

Yager DD (1999) Structure, development, and evolution of insect auditory systems. Microsc Res Tech 47:380-400. doi: 10.1002/(SICI) 1097-0029(19991215)47:6<380::AIDJEMT3>3.0.CO;2-P 